\title{
On the Effect of Goal Setting on Self-Directed Learning, Achievement Motivation, and Academic Achievement among Students
}

\author{
Fatemeh Hematian ${ }^{1}$, Ali Mohammad Rezaei ${ }^{2} \&$ Mohammad Ali Mohammadyfar $^{3}$ \\ ${ }^{1}$ M.A. Student of Educational psychology, Semnan University, Iran \\ ${ }^{2}$ Assistant Professor, Faculty of Education and Psychology, Semnan University, Semnan, Iran \\ ${ }^{3}$ Assistant Professor, Faculty of Education and Psychology, Semnan University, Semnan, Iran \\ Correspondence: Ali Mohammad Rezaei, Assistant Professor, Faculty of Education and Psychology, Semnan \\ University, Semnan, Iran. E-mail: rezaei_am@semnan.ac.ir
}

Received: June 18, 2016

doi:10.5539/mas.v11n1p37
Accepted: July 13, 2016

Online Published: October 5, 2016

URL: http://dx.doi.org/10.5539/mas.v11n1p37

\begin{abstract}
This study aimed to investigate the effect of goal setting on self-directed learning, achievement motivation, and academic achievement in students. All secondary school students at eighth grade in Semnan city in 2015 constituted the population of the study. From among this population, the number of 40 students with the lowest scores in self-directed learning and achievement motivation was randomly selected as the sample. Then, these students were equally placed in two experimental and control groups. In the next stage, the pretest was administered to both groups and the experimental group received nine training sessions of self-directed learning. It is noteworthy that the control group received no intervention. In this study, pretest-posttest along with control group design was used. Fisher, King \& Tague's Self-Directed Learning Readiness Scale and Herman's Questionnaire Measure of Achievement Motivation along with students' grade point average scores (first semester as the pretest and second semester as the posttest) were used for data collection purposes. Next, data analysis was performed using multivariate MANCOVA and univariate ANCOVA. The results showed that teaching of goal setting had a significant effect on the improvement of self-directed learning and achievement motivation; however, it had no significant effect on students' academic achievement. According to the obtained results, it is recommended that goal setting be taught to promote self-directed learning and achievement motivation.
\end{abstract}

Keywords: goal setting, self-directed learning, achievement motivation, and academic achievement

\section{Introduction}

\subsection{Introduce the Problem}

Knowledge and its acquisition play such an important role in the contemporary society that one can claim that people are living in the knowledge era at the present time. Rapid cultural, political, social, and economic changes have converted self-directed learning to an essential requirement nowadays (Alotaibi, 2016). This issue has made self-directed learning one of the most attractive topics in the field of learning and teaching (Roberson, 2005; Teo, et al., 2010). According to this urgent need, training courses have been designed to enhance students' self-directed learning and this is effective in preparing students for learning at school (Khiat, 2015). Therefore, people should regard learning control and self-directedness as lifelong priorities (Siriwongs, 2015). In different societies, expert groups and psychologists have always emphasized various aspects of education and assigned credit to the identification of the factors influencing education (Lounsbury, Steel, Loveland \& Gibson, 2004) because not only students and their families, but also the society spends huge costs on the study and education of students. Success and academic achievement in each community reflect the success of the whole educational system in terms of goal setting and attention to the fulfillment of individual needs. Factors affecting learning and academic achievement are very broad and the identification of these factors is of great importance in solving the problems and deficiencies available in the educational system. One of the factors contributing to academic achievement and the enhancement of educational output is to create motivation in people for learning. In fact, some researchers believe that learning and motivation are so interconnected that that there is no possibility of learning perception without motivation perception (Moreno, 2010). The strong positive correlation between 
motivation and academic achievement is evidence for this interconnection. Students with higher motivation for learning usually learn more rapidly and make greater progress in comparison with those with lower levels of motivation for learning (McDermott, Mordell, Stoltzfus, 2001, cited in Moreno, 2010).

Self-directed learning is a purposeful process that is usually identified by behavioral activities involved in information recognition and search. In this regard, the learner consciously accepts responsibility for decisions relating to the objectives and activities (Long \& Huey, 2009). In fact, self-directed learning is a psychological state wherein learners feel they are individually responsible for their own learning (Radnitzer, 2010). Havvs (1996) and Garrison (1997) defined self-directed learning as self-management (field management, including social environment, resources, and performance) and self- monitoring (regulation, evaluation, and review of cognitive strategies).

Self-directed students need to enjoy the skills pertaining to control, regulation, internal and external motivation, and success during learning activities and experiences in order to learn things (Ayyildiz \& Tarhan, 2015). Yuan, Williams \& Fang (2011) argued that students become familiar with their own learning needs, goal determination, selection of learning strategies, and evaluation of learning process results by means of self-directed learning. Cofarella \& Gartner (2006) claimed that learners with high levels of self-directed learning are defined as those equipped with learning initiatives, who are independent and insist on learning. A learner is someone who accepts responsibility for his/her learning, considers problems as challenges rather than obstacles, is capable of self-discipline, and takes advantage of a high degree of curiosity. Such a person has a strong desire for learning or change and enjoys high levels of self-confidence. In addition, such a person is able to utilize basic study skills, to organize time, to set high speed for learning, and develop a plan to complete a task. S/he enjoys learning and is willing to set goals. From the perspective Fisher \& King (2010), three main variables, namely self-management, self-control, and desire to learn have been considered for self-directed learning.

Achievement motivation is also considered to be a very important factor in students' achievement (Niederkofler, et al., 2015). It is a complex psychological phenomenon that was first clarified through a bright framework by Murray in 1938. Murray defined achievement motivation as the desire or tendency to surmount or overcome barriers and to exercise power and efforts for the quick and desired accomplishment of difficult jobs (Murray, 1938). Mc Clelland also regards achievement motivation and need as the consequence of emotional conflict between hope to succeed and the desire to escape from defeat and failure. One the one hand, hope for success hinges upon the positive emotions and beliefs around success; on the other hand, fear of failure is dependent upon is interrelated with negative emotions and the inaccessibility of achievement chance (Steinmay \& Spinath, 2009). In fact, achievement motivation is one of the normal features of daily life, in which people endeavor to achieve competence in their activities (Bat, Ishai, \& Levi, 2014). Some scholars consider achievement motivation as one's intention and willingness to strive for success or pleasant feeling of success in the fulfillment of hi/her functions (Acharya \& Joshi, 2009). Indeed, school and university students are stimulated by achievement motivation to complete their academic tasks in order to achieve their goals and a certain level of expertise, skill, and success. The behavior of adults with high achievement motivation is energetic, purposeful, directional, and stable. Moreover, students with high motivation engage themselves in difficult academic tasks and try hard to gain mastery (Amrai, et al., 2011). On the other hand, it is about nearly a century that psychologists are widely making the effort to identify predictors of academic achievement. Such scholars as Bine \& Simon, Thorndike, Harris, Elshot, and Hamaker have worked on this area (Premuzic \& Furnham, 2003). Academic achievement is referred to as an indicator of predicting success and promotion in each specialty and career. Academic achievement has become a competitive indicator for children's future. Additionally, it is one of the most important objectives in the educational process that is regarded as the main goal each person is expected to meet in all cultures. From another perspective, academic achievement is considered to be a multifaceted structure with different learning domains (Steinmayr, et al., 2015). Sahaya Saila \& Chamundeswari (2013) define academic achievement as a key mechanism through which adolescents become aware of their own talents, aptitudes, and competencies, which constitute an important portion of professional ideals. In addition, Chen (2007) has defined academic achievement as students' academic performance in school (Lee, 2012). Given the importance and necessity of routinizing self-directed learning, achievement motivation, and academic achievement; the question arises as to how this variable can be enhanced in people. In order to answer this question, researchers and psychologists have attempted to improve this feature by proposing techniques based on psychological characteristics. For example, information technology and communication skills are among these techniques. In this regard, Kozma (2003), Braak (2007), Tondeur (2007), Watts \& Lloyd (2004) and Newrouse's (2002) findings regarding the effects of the use of information technology and communications on strengthening learners' self-directed learning and academic achievement have offered another method of improving 
self-directed learning, teaching critical thinking, problem solving, and meta-cognition whose effectiveness has been proved (Hendricson, 2006; Miflin \& Compblell, 1999; Azman, 2000; Bostrom \& Lassen, 2006; Corey, 2007; Massa, 2008, Nadi, Gordanshekan \& Golparvar, 2011). Research also has shown that web-based training (Karahoca, et al., 2010; Ashoori, Kajbaf, Mansha'ea \& Talebi, 2014), training of concept mapping and collaborative learning (Ashoori, Kajbaf, Mansha'ea \& Talebi, 2014), computer games and animation (Saleh Sedghpour \& Gholamrezayee, 2013), teaching of learning skills in groups (Ameri, Hosseinpur \& Atari, 2013), teaching of neuro-verbal programming strategies (Zamini, Hosseininasab \& Hashemi, 2007), and training of cognitive and metacognitive strategies (Karami, Karami \& Hashemi, 2013) are effective in the enhancement of achievement motivation and academic achievement. However, goal setting training is a new method that can be used to effectively promote self-directed learning, achievement motivation, and academic achievement.

\subsection{Explore Importance of the Problem}

The concept of goal has been treated with different definitions since this term is commonly used in everyday life of humans with many applications in different situations. Some researchers believe that end is, in fact, a situation or an external situation or lies outside of human existence. Thus, people are trying to achieve it with their efforts. Despite the fact that tastes and motivations are guided from inside human beings, ends are the external stimuli that attract people via induction of human motivations (Tuckman, 2014). End is a strong predictor of acts that leads to the termination of thinking about alternative goals (goal competition) and brings about a sense of commitment in the individuals to stick to the end or goal (Moussa, 2012). In fact, end expresses one's intention and refers to the howness, amount, and/or level of performance (Locke \& Latham, 1990; Locke, Shaw, Sarri, Latham \& Latham, 1981). Martens (1991) defined goal setting as a regular approach of goal setting and efforts to meet the goals that are effective in progress and development of self-confidence and in the achievement of competency. In other words, goal setting is to perceive some favorable results and to plan a series of actions to achieve that goal or specify the aspirations will be achieved through systematic efforts (Saneh, 2006). The purpose and meaning of life are among the most important religious, administrative, philosophical, and psychological issues and psychologists such as Allport, Lewin, Erich Fromm, Adler, Erickson, and Jung have implicitly touched the purpose and meaning of (Zika \& Chamberlain, 1992). At present, in psychology, management, and many other fields, goal setting is concentrated on to increase performance and to improve individual and team progress in different fields of psychology, education, etc. (Nahrgang, et al., 2013; Weinberg, 2010). Although the historical origin of goals dates back to the early twentieth century, Edwin Locke and Gary Latham are highly reputed figures in the development of goal-setting theory (Locke \& Latham, 1985, 1990, 2005; Latham, 2000). In this regard, Locke \& Latham (1990) suggested four conditions for successful goal setting as follows: clarity, challenge, achievability, commitment. The findings of other studies (Klein, et al., 2001, Locke \& Latham, 2005; 2006) showed that when these four conditions are met, goal setting will be an effective way to improve performance and to glorify both individual and team behavior. Locke \& Latham $(1985,1990)$ and Boyce (1992) regarded goal setting as an important factor in the improvement of learning. In fact, goal setting is one of the fundamental and effective conditions that motivate people to learn. Taylor (1995) found self-directed learners as self-motivated, persevering, autonomous, self-disciplined, self-confident, and goal-oriented. In self-directed learning process, students are encouraged to expand their knowledge and their ability to evaluate their own shortcomings pertaining to knowledge and they then examine knowledge deficiencies looking into the related resources. They may use their knowledge of available resources in an informed judgmental state to opt for the best solutions for tackling problems (Karimi, Arendt, Cawley, Buhler, Elbarbry \& Roberts, 2010). Self-directed learning requires goal setting, task analysis, implementation of pre-made plans, and self-assessment in the learning process (Loyens, Magda \& Rikers, 2008). In short, goal setting is an emphasis that clear and achievable, (but) challenging goals can often increase one's motivation because such goals lead to an increase in concentration, effort, and sustainability (Baghurst, Tapps \& Kensinger, 2015). When people set themselves some goals, they become more aware of their strengths and weaknesses and judge their abilities and efforts to successfully fulfill these objectives. Therefore, such individuals will have access to more effective study strategies and rules and adopt a better and more influential learning approach. In addition, when they really find the ability to achieve the goals, their motivation will increase (Bloom, 2013).

According to the above-mentioned points, goal setting is an overall strategy that can be applied in various fields. Effective goal setting requires the person to determine a long-term goal and to break it down into short-term goals and accessible sub-goals witch such capabilities as progress monitoring, assessment, setting the required strategies, and setting a new goal if the previous goal has been met. This multi-step plan is a key to enhance healthy physical and mental performance in all human affairs, including personality, education, and so on throughout lifetime (Schunk, 2001). Despite the importance of goal setting in personal and social life, the 
majority of studies conducted in Iran have been focused in the field of management and sports. Few studies have been done in the field of psychology and even these few studies lack a coherent and comprehensive goal setting program. According to the prominent role of goal-setting in improving people's lives, the current study is an attempt to develop a training package of goal setting through a combination of Mager \& Granlund's Approach, Individual Development Planning (IDP), Individual Idealized Vision (IIV), SMART model, HARD model, and SWOT model. It also aims to investigate the impact of goal setting on self-directed learning, achievement motivation, and academic achievement.

\section{Method}

\subsection{Identify Subsections}

Method section divided into labeled subsections, included a section with descriptions of the participants or subjects and a section describing the procedures used in the study. Describing the procedures section often includes description of (a) any experimental manipulations or interventions used and how they were delivered; (b) sampling procedures and sample size and precision; (c) measurement approaches (including the psychometric properties of the instruments used, scoring of them, reliability and validity of the measures); and (d) the research design.

\subsection{Participant Characteristics and Sampling Procedure}

All secondary school students at the eighth grade in Semnan city in 2015 constituted the population of the study. For sampling purposes, the girls' high school of Zainab (first period) was first selected randomly. Then, the number of 200 eighth graders of this high school was randomly selected and was examined via the Self-Directed Learning and Achievement Motivation Questionnaires. After evaluation, the number of 40 students with the lowest scores in these questionnaires was randomly divided in two 20-participant groups. In the following, one of the groups was randomly considered as the experimental group and the other group was considered as the control group. Afterwards, the pretest was administered to both groups and the experimental group received nine training sessions of self-directed learning. The control group received no intervention.

\subsection{Research Design}

A two-group experimental research design along with pre-/post-test and control group was used for the conduct of this study. In this study, teaching of goal setting is the independent variable while self-directed learning, goal setting, achievement motivation, and academic achievement constitute the dependent variables of the study.

\subsection{Experimental Manipulations or Interventions}

Training sessions were held in nine 90-minute sessions as follows:

First session: The administration of the pre-test to the members of both groups/ establishment of communication and interaction with members of the experimental group/ introduction of the examiner, examinees, and members of the experimental group/ introduction of the training course and mention of its rules/ creation of desire and willingness in members of the experimental group for cooperation (provision of concrete examples of the benefits and applicability of goal setting in education, job, and life)/ presentation of a simple preliminary definition of goal and goal setting.

Second session: Review of the materials presented in the previous session/ introduction of goal, goal setting, and goal analysis/ introduction and explanation of different types of goals (short term, medium term, and long term)/ teaching and explanation of goal analysis steps by means of Mager \& Granlund's approach (teaching how to convert general goals to accurate academic goals)/ provision of the tasks in line with the educational content of the session to the members for better learning.

Third session: review of the assignments belonging to the previous session and provision of suitable feedback/ teaching of HARD and SMART model for setting goals/ provision of assignments tailored to the educational content of the session to the members for better learning.

Fourth session: overview of the issues relating to the previous session and provision of appropriate feedback/ completion of "Individual Idealized Vision (IIV)" according to SMART model by each member/ discussion of the completed IIV forms between the members and the teacher, provision of proper feedback, and its modification and regulation if necessary/ teaching how to identify the areas in need of improvement (the gap between the status quo and the desired situation)/ emphasis on the importance of self-assessment in the process of goal setting: At this stage, the experimental group members made a self-assessment of their goal settings based on SMART, and the members were taught how to use self-assessment results to improve their own situation. 
Fifth Session: overview of the issues belonging to the previous session/ presentation of SWOT matrix and its full explanation/ completion of the SWOT matrix by each of the experimental group members/ discussion of the completed SWOT matrix between the members and the teacher, provision of proper feedback, and its modification and regulation if necessary.

Sixth session: overview of the issues belonging to the previous session/ training how to convert the opportunities and goals derived from the SWOT matrix to performance goals/ training how to develop success criteria and achieve goals, how to use necessary resources and supports, and how to develop a timetable for meeting each goal/ completion of "individual goal setting program" form by each of the experimental group members/ discussion of the completed form between the members and the teacher, provision of proper feedback, and its modification and regulation if necessary.

Seventh session: overview of the educational content of the previous sessions and problem-solving if necessary/ registration of the goals belonging to each of the members in a booklet entitled "goal setting and analysis"/ training how to develop a proper schedule according to each person's goals for implementation and report provision.

Eighth session: re-evaluation, feedback, and repetition of the steps: review and evaluation of members' goal setting plans by the researcher, provision of the required feedback the members, preparation of the members to repeat some steps or to be led to the next goal.

Ninth session: administration of the post-test by the researcher to both groups/ acknowledgement and appreciation of the cooperation of all members.

\subsection{Measures}

2.5.1 Self-Directed Learning Readiness Scale (SDLRS): SDLRS is a 41-item test that has been developed by Fisher, King \& Tague. In this scale, participants respond to a five-point Likert scale $(1=$ very low to $5=$ very high). Fisher, King \& Tague's findings in Australia showed that the internal consistency reliability of the whole scale was equal to 0.83 and this coefficient was equal to $0.87,0.85$, and 0.80 for the subscales of self-management, desire to learning, and self-control, respectively. Furthermore, the correlation between each item's score and the total score ranged from 0.26 to 0.84 . In terms of validity, the construct validity of this scale has been reported to be desired using confirmatory factor analysis (Fisher \& King, 2010). In Iran, Nadi \& Sajadian (2006) validated this scale for the first time and obtained the reliability of the whole scale equal to 0.82 and also the reliability coefficients of $0.78,0.71$, and 0.60 for self-management, desire to learning, and self-control, respectively. In Nadi \& Sajadian's study, results of principal component analysis were indicative of the loading of the three components introduced in Fischer et al. (2001).

2.5.2 Achievement Motivation Questionnaire: This questionnaire has been prepared by Hermans in 1970 . Hermans first prepared 91 predicates for the compilation of this questionnaire and then he reduced them to a number of 35 items. Finally, he minimized the number of items to 29 ones in his next studies. The items are in the form of semi-finished sentences, each with four alternatives. Hermans (1970) reported the validity of the scale to be appropriate using construct validity and obtained its reliability equal to 0.86 via Cronbach's alpha. In Iran, the reliability coefficient of 0.78 has been obtained via Cronbach's alpha (Shokrkon, Boroomandnasab, Najarian \& Shaheni Yeilagh, 2002). Similarly, Mohamadzadeh Adamlayi, Shaheni Yeilagh \& Mehrabizadeh Honarmand (2009) obtained the reliability of the scale equal to 0.76 and 0.75 via Cronbach's alpha and split-half method, respectively.

2.5.3 Academic Achievement: The index of grade point average (GPA) was used to measure academic achievement. In fact, the data regarding subjects' academic achievement were obtained from their first and second semesters' report cards. It is notable that the first semester scores (before the intervention) were regarded as pre-test and the second semester scores were considered as post-test.

\section{Results}

In this section, the descriptive and inferential findings and the analyses done to answer the research questions. Table 1 indicates mean scores, standard deviation, and standard error mean pertaining to the research variables in the pre-test and post-test for experimental and control groups. As it is observed, the mean scores of self-directed learning, achievement motivation, and academic achievement tests have increased from 134.05, 75.3, and 16.62 in the pre-test to $154.35,87.2$, and 16.64 in the post-test, respectively. This is so while the control group members' scores in the pre-test have experienced no significant change in the post-test. 
Table 1. Descriptive statistics of the research variables in the pre and post-test for both groups

\begin{tabular}{|c|c|c|c|c|c|c|}
\hline Implementation & variables & Groups & $\mathrm{N}$ & Mean & SD & Standard error \\
\hline \multirow{6}{*}{ Pre-test } & \multirow{2}{*}{ Self-directed learning } & Experimental & 20 & 134.05 & 13.67 & 3.06 \\
\hline & & Control & 20 & 137.12 & 9.02 & 2.02 \\
\hline & \multirow{2}{*}{ Achievement motivation } & Experimental & 20 & 75.3 & 6.82 & 1.52 \\
\hline & & Control & 20 & 78.4 & 8.66 & 1.93 \\
\hline & \multirow{2}{*}{ Academic achievement } & Experimental & 20 & 16.62 & 2.38 & 0.53 \\
\hline & & Control & 20 & 16.21 & 2.64 & 0.59 \\
\hline \multirow{6}{*}{ Post-test } & \multirow{2}{*}{ Self-directed learning } & Experimental & 20 & 154.35 & 17.11 & 3.82 \\
\hline & & Control & 20 & 134.50 & 13.22 & 2.96 \\
\hline & \multirow{2}{*}{ Achievement motivation } & Experimental & 20 & 87.2 & 7.87 & 1.76 \\
\hline & & Control & 20 & 76.6 & 7.35 & 1.64 \\
\hline & \multirow{2}{*}{ Academic achievement } & Experimental & 20 & 16.46 & 2.48 & 0.55 \\
\hline & & Control & 20 & 16.14 & 2.68 & 0.6 \\
\hline
\end{tabular}

After the examination of the descriptive findings, the assumptions of MANCOVA test were investigated. One of the assumptions of using this test is the homogeneity of covariance matrices, which is checked by M Box's test. The results of this test here showed that this assumption has been met $(\mathrm{P}>0.05)$. Another assumption of using this test is the equality of error variances and Levene's Test is used to explore the verification of this assumption. As shown in table 2, the results suggest that this assumption has been met, as well $(\mathrm{P}>0.05)$.

Table 2. Levene's Test of Equality of Error Variances

\begin{tabular}{ccccc}
\hline variables & $\mathrm{F}$ & $\mathrm{df}_{1}$ & $\mathrm{df}_{2}$ & $\mathrm{P}$ \\
\hline Self-directed learning & 2.61 & 1 & 38 & 0.11 \\
Achievement motivation & 0.92 & 1 & 38 & 0.34 \\
Academic achievement & 2.27 & 1 & 38 & 0.14 \\
\hline
\end{tabular}

After the achievement of assurance about the fulfillment of the assumptions, multivariate analysis of covariance (MANCOVA) was used to compare the experimental and control groups in the variables. The results showed that there was a significant difference between the experimental and control groups in the dependent variables $\mathrm{F}(3$, $33)=13.613 ; \mathrm{p} \leq \mathbf{0} / \mathbf{0 0 0 5}$ ) and $55 \%$ of the variance of the dependent variables (self-directed learning, achievement motivation, and academic achievement) is accounted for by teaching of goal setting. In order to determine the existence of the significant difference between the two groups in any of the dependent variable separately, univariate analysis of covariance (ANCOVA) was used (Table 3). The results indicate that there is no significant difference between the experimental and control groups in terms of academic achievement whereas there is a statistically significant difference between the two groups in the other two variables, i.e., self-directed learning and achievement motivation. In fact, self-directed learning and achievement motivation have experienced a considerable increase in the post-test, which is representative of the effectiveness of goal setting training in self-directedness and achievement motivation.

Table 3. ANOVA results representing the difference between the groups in self-directed learning, achievement motivation, and academic achievement

\begin{tabular}{cllccccc}
\hline Sources & \multicolumn{1}{c}{ variables } & $\begin{array}{c}\text { Sum of } \\
\text { squares }\end{array}$ & df & Mean Square & F & P & $\begin{array}{c}\text { Partial Eta } \\
\text { Squared }\end{array}$ \\
& Self-directed learning & 4161.01 & 1 & 4161.01 & 17.86 & 0.0005 & 0.338 \\
Group & Achievement motivation & 1500.9 & 1 & 1500.9 & 37.6 & 0.0005 & 0.518 \\
& Academic achievement & 0.043 & 1 & 0.043 & 0.114 & 0.737 & 0.003 \\
& Self-directed learning & 8152.7 & 35 & 232.93 & - & - & - \\
\multirow{2}{*}{ Error } & Achievement motivation & 1397.28 & 35 & 39.92 & - & - & - \\
& Academic achievement & 13.15 & 35 & 0.376 & - & - & - \\
\hline
\end{tabular}




\section{Discussion}

Surprisingly rapid changes are taking place in the field of science and technology and they have intensified and made more sensitive the urgent need of education systems for self-directed and motivated learning. The vast amount of information and knowledge moves educational systems towards such a direction that the traditional method can no longer transfer this vast amount of knowledge to learners. Therefore, the conversion of all leaners to self-directed and motivated learners enables learners to set their learning needs and goals in accordance with the existing knowledge. On the other hand, the presence of knowledgeable, efficient, and creative individuals is an important condition for the growth and prosperity of any society; therefore, nurturing and strengthening of self-directedness and achievement motivation will energize and appropriately direct people's appropriate behaviors, interests, and needs (Tamanayifar \& Gandomi, 2011). Students' academic achievement is also one of the most important indicators in the assessment of education. In other words, society and particularly the education system are interested in and concerned about the successful development and evolution of students and their position in society. Thus, it is expected that students can excel in various aspects including cognitive dimensions, emotional aspects, personality, skill acquisition, and abilities (Heidari, et al., 2010). Towards the improvement of self-directed learning, achievement motivation, and academic achievement, this study was conducted on these three variables with the aim of developing the goal setting training package; amalgamating goal analysis based on Mager \& Granlund's approach, IDP, IIV, SMART model, HARD model, and SWOT model together, exploring the effect of goal setting training on the three above-mentioned variables. The findings showed that goal setting training is effective in the enhancement of students' achievement motivation and self-directed learning whereas it has no significant effect on academic achievement. In this regard, Huang (2008), Kazemi \& Omidi Najafabadi (2012) concluded that there was a positive relationship between self-directed learning readiness and goal clarification. Yuchiung (2005) conducted a study at the University of Queensland and concluded that the fulfilment of goals is significantly associated with the strengthening of readiness for self-directed learning. He also showed that the use of self-directed learning activities makes learning more active and brings about increased responsibility for learning assignments. Gaa $(1973,1979)$ also found that the goal setting sessions and classes would enhance students' learning and self-assessment abilities. In the same way, Torabi's findings (2012) supported the positive effectiveness of goal setting in the implementation and learning of tasks. Researchers such as Malka \& Covington (2005) and Miller, Greene, Montalvo, Ravindran \& Nichols (1996) showed that goal setting exerts a critical impact on achievement motivation and some researchers such as Tuckman (2014) and Baghurst, Tapps \& Kensinger (2015) found that goal setting leads to an increase in motivation and improvement of individuals' performance. Lock \& Latham (1990), Lock, Show, Sarri \& Latham (1981) and Mento, Steel \& Karren (1987) regarded goal setting as one of the most effective psychological strategies for the improvement of performance and motivation. In terms of the impact of goal setting on students' achievement motivation, researchers have found that selection of very easy or very difficult goals leads individuals to lose their motivation for success. In contrast, when people opt for goals with appropriately medium level of difficulty, their achievement motivation rise (Stipek, 2002). Accordingly, goal setting can increase motivation in people (Heather \& Alder, 2006).

In terms of the causality of the ineffectiveness of goal setting training in students' academic achievement, one can argue that the participants lay at a relatively appropriate level in GPA (above 16). For this reason, the training course may have not been considerably effective in the augmentation of academic achievement. Furthermore, the training course was held at the time close to final exams and the participants were not equipped with ample opportunity to set overall goals, do coherent planning, and plan any progress in their minds.

Considering the results of the studies conducted in this area in recent years as well as the current results, it is possible to mention that teaching of goal setting is effective in the improvement of achievement motivation and self-directed learning. Thus, it can be concluded that holding training classes on goal setting is useful in improving the students' position. Therefore, results of this study can be confirmation of the benefits of goal setting training. It seems that it is necessary to pay attention to the teaching of appropriate goal setting skills in order to augment self-directed learning and motivation in learning environments. Therefore, educational authorities, teachers, and university professors are recommend teaching students goal setting skills during study. In addition, it is suggested that future studies examine the effect of goal setting training on academic achievement of the students with low levels of educational attainment (GPA under 16).

\section{References}

Acharya, N., \& Joshi, S. (2009). Influence of parents' education on achievement motivation of adolescents. Indian Journal of Social Science Researches, 6, 72-79. 
Alder, H., \& Beryl, H. (2006). Nlp in 21 Days, translated by Ali Shadrooh. Phoenix Publication.

Alotaibi, K. H. (2016). The learning environment as a mediating variable between self-directed learning readiness and academic performance of a sample of Saudi nursing and medical emergency students. Nurse Education Today, 36, 249-254.

Ameri, E., Hussainpour, M., \& Atari, Y. (2013). The effectiveness of teaching learning skills in groups in the increase of motivation (PQ5R) after the end of the progress of secondary school students. New Advances in Psychology, 26, 109-124.

Amrai, K., Elahimotlagh, S., Azizi, Z. H., \& Pahon, H. (2011). The relationship between academic motivation and academic achievement students. Journal of Social and Behavioral Sciences, 15, 399-402.

Ashoori, J., Kajbaf, M., Mansha'ea, Gh., \& Talebi, H. (2014). On the effectiveness of web-based training methods, traditional and collaborative learning methods in achievement motivation and academic achievement in biology course. Magazine of Elearning Distribution in Academy, 5(2).

Ashoori, J., Kajbaf, M., Mansha'ea, Gh., \& Talebi, H. (2014). On the effect of concept mapping, traditional and collaborative learning methods on achievement motivation and academic achievement in biology course. Research in Curriculum Planning, 14 (41), 63-73.

Ayyildiz, Y., \& Tarhan, L. (2015). Development of the self-directed learning skills scale. INT. J. Of Lifelong Education, 34(6), 663-679.

Azman, N. (2000). Self-Directed learning readiness and Academic performance, university of kebangsaan, Malaysia, selengor. $\mathrm{p}(2)$. Available: Abstract in google and Eric.

Baghurst, T., Tapps, T., \& Kensinger, W. (2015). Setting Goals for Achievement in Physical Education Settings. A Journal for Physical and Sport Educators, 28(1), 27-33.

Bat or, M., Ishai, R., \& Levi, N. (2014). The Symbolic Content in Adults' PPAT as related to Attachment Styles and Achievement Motivation. The Arts in Psychotherapy Journal.

Bloom, M. (2013). Self-regulated learning: Goal setting and self-monitoring. The Language Teacher. Retrieved from http://www.jalt-publications.org/tlt

Bolhuis, S. (1996). Towards Active and Self-Directed Learning Preparing for lifelong learning. Paper presented at the annual Meeting of the American Educational Research association. New Yourk, NY. Apricl 8-12.

Bostrom, L., \& Lassen, L. M. (1996). Unraveling learning, learning styles, learning strategies and meta-cognition. Education \& Training. Landon(2006), 48(1/3), 278-299.

Braak, V. (2007). Curricula and the use of ICT in education. British Journal of Educational Technology, 38(6).

Corey, B. (2007). Promo ting self-directed learning in three online health promotion and wellness courses. Journal of Authentic learning, 4(2).

Fisher, M. J., \& King, J. (2010). The self-directed learning readiness scale for nursing education revisited: A confirmatory factor analysis. Nurse Education Today, 30, 44-48.

Fisher, M., King, J., \& Tague, G. (2001). Development of a self-directed learning readiness scale for nursing education. Nurse Education Today, 21, 516-525.

Garrison, D. R. (1997). Self-Directed learning. Toward A Comprehensive model. In Adult Education quarterly, fall, 48(1), 16-18.

Haidari, Gh., Modanloo, Y., Niazazari, M., \& Jafari, G. A. (2010). On the comparison of English language teaching with educational software and with traditional practices in students' academic achievement. ICT in Education, 1, 103-118.

Hendricson, W. D., et al. (2006). Educational strategies associated with development of Problem solving, critical thinking, and self-directed learning. Journal of Dental Education, 70(9), 925-36.

Huang, M. H. (2008). Factor influencing self-directed learning readiness amongst Taiwanese nursing students. Queensland University of technology school of nursing. Institute of Health and Biomedical Innovation, 191-205.

Karahoca, D., Karahoca, A., Karaoglu, A., Gulluoglu, B., \& Arifoglu, E. (2010). Evaluation of web based learning on student achievement and achievement motivation in primary school computer courses. Journal of Social and Behavioral Sciences, 2, 5813-5819. 
Karami, B., Karami, A., \& Hashemi, N. (2013). On the effectiveness of teaching of cognitive and metacognitive strategies in creativity, achievement motivation, and academic self-concept. Journal of Innovation and Creativity in Human Science, 2(4).

Karimi, R., Arendt, C. S., Cawley, P., Buhler, A. V., Elbarbry, F., \& Roberts, S. C. (2010). Learning Bridge: curricular integration of didactic and experiential education. American Journal of Pharmaceutical Education, 74, 1-8.

Kazemi, H., \& Omidi, N. M. (2012). Factors affecting self-directed learning readiness (SDLR) among students of College of Agriculture; Science and Research Branch of Tehran. Journal of Agricultural Extension and Education, 5(4).

Khiat, H. (2015). Academic performance and the practice of self-directed learning: The adult student perspective. Journal of Further and Higher Education.

Klein, H. J., Wesson, M. J., Hollenbeck, J. R., Wright, P. M., \& DeShon, R. P. (2001). The assessment of goal commitment: A measurement model meta-analysis. Organizational Behavior and Human Decision Processes, 85, 32-55.

Kozma, R. (Ed.) (2003). Technology, innovation, and educational change: A global perspective. Eugene, OR: International Society for Educational Technology.

Li, L. K. Y. (2012). A Study Attitude, Self-efficacy, Effort and Academic Achievement of City U Students towards Research Methods and Statistics of the. Discovery - SS Student E-Journal, 1(54), 154-183.

Locke, E. A., \& Latham, G. P. (1985). The Application of goal setting to sports. Sport Psychol, 7, 205-222.

Locke, E. A., \& Latham, G. P. (1990). A theory of goal setting and task performance. Englewood Cliffs, N. J.: Prentice Hall.

Locke, E. A., \& Latham, G. P. (2005). Goal setting theory: theory building by induction.

Locke, E. A., \& Latham, G. P. (2006). Enhancing the Benefits and Overcoming the Pitfalls of Goal Setting. Organizational Dynamics, 35(4), 332-340.

Locke, E. A., Shaw, K. N., Saari, L. M., \& Latham, G. P. (1981). Goal setting and task performance: 1969-1980. Psychological Bulletin, 90, 125-152.

Long, B., \& Huey, B. (2009). Skills for self-directed learning. Retrieved from http://faculty-staff.ou.edu/L/Huey.B.Long-1/Articles/sd/self-directed.html

Lounsbury, J. W., Steel, R. P., Loveland, J. M., \& Gibson, L. W. (2004). An investigation of personality traits in relation to adolescent school absenteeism. Journal of Youth and Adolescence, 33, 457-466.

Loyens, S. M. M., Magda, J., \& Rikers, R. M. J. P. (2008). Self-directed learning in problem-based learning and its relationships with self-regulated learning. Educational Psychology Review, 20, 411-427.

Malka, A., \& Covington, M. (2005). Perceiving school performance as instrumental to future goal attainment: Effects on graded performance. Contemporary Educational Psychology, 30, 60-80.

Massa, N. M. (2008). Problem-based learning (PBL). The New England Journal of Higher Education. Boston: winter, 1008, 11(4), 1-29.

Mento, A. J., Steel, R. P., \& Karren, R. J. (1987). A meta-analytic study of the effects of goal setting on task performance. Organizational Behavior and Human Decision Processes, 39, 52-83.

Miflin, B. M., \& Compblell, C. B. (1999). Alesson from the introduction of a problem-based, graduate Entry course: the effect of different view of self-direction, Blackwell science ITd. Medical Education, 33, 802-807.

Miller, R. B., Greene, B., Montalvo, G., Ravindran, B., \& Nichols, J. (1996). Engagement in academic work: The role of learning goals, future consequences, pleasing others, and perceived ability. Contemporary Educational Psychology, 21, 388-422.

Mohamadzadeh, A. R., Shaheni, Y. M., \& Mehrabizadeh, H. M. (2009). On the comparison of male students with different learning styles in terms of personality traits, achievement motivation, and academic achievement. Journal of Psychological Achievements, 4(1), 125-154.

Moreno, R. (2010). Educational psychology. U.S.A. Wiley \& Sons Inc.

Moussa, F. M. (2012). The Interactive Effects of Self-Esteem, Goal Instructions, and Incentives on Personal 
Goals and Goal Attainment. Organization Management Journal, 9, 148-169.

Murray, H. A. (1938). Explorations in Personality. New York: Oxford University Press.

Nadi, M., \& Sajjadian, I. (2006). Standardization of Self-Directed Learning Scale in female high school students of Isfahan. Journal of Educational Innovations, 5, 18.

Nadi, M., Gordanshekan, M., \& Golparvar, M. (2011). The impact of critical thinking training, problem solving and metacognition on self-directed learning in students. Research in Curriculum Planning, 2.

Nahrgang, J. D., Scott, D. D., Hollenbeck, J. R., Spitzmuller, M., Jundt, D. K., \& Ilgen, D. R. (2013). Goal setting in teams: The impact of learning and performance goals on process and performance. Organizational Behavior and Human Decision Processes, 122, 12-21.

Newrouse, P. (2002). Specialist educational services parth. Western Australia.

Niederkofler, B., Herrmann, C. H., Seiler, S., \& Gerlach, E. (2015). What influences motivation in Physical Education. A multilevel approach for identifying climate determinants of achievement motivation. Psychological Test and Assessment Modeling, 57(1), 70-93.

Premuzic, T., \& Furnham, A. (2003). Personality traits and academic examination performance. European Journal of Personality, 17, 237-250.

Radnitzer, K. (2010). Emotional Intelligence and Self-Directed Learning Readiness among College Students Participating in a Leadership Development Program. Journal of Leadership Development, 12(8), 124-130.

Rainer, M. (1991). Coaches Guide to Sport Psychology, translated by Hojabr. F. (1995). Tehran, Jihad Daneshgahi Press (Majid).

Roberson, D. N. (2005). Self-Directed Learning--Past and Present. Retrieved from http://eric.ed.gov/PDFS/ED490435.pdf

Sahaya, S. T., \& Chamundeswari, S. (2013). Psychological Counseling needs and Academic achievement of students at the Secondary level. International Journal of Learning \& Development, 3(3), 154-167.

Saleh, S. B., \& Gholamrezayee, F. (2013). The role of dimension computer games in achievement motivation and academic achievement in math with respect to students' mathematical and language pre-knowledge. Journal of Information Technology and Communication in Education, 3, 89-113.

Saneh, A. (2006). On the comparison of the effects of goal setting and awareness of the results on learning how to act on service in volleyball among school girls. PhD Thesis of Physical Education and Sport Sciences, Tehran University.

Schunk, D. H. (2001). Self-Regulation through Goal Setting. ERIC/CASS Digest ED462671.

Shokrkon, H., Boroomandnasab, M., Najarian, B., \& Shaheni, Y. M. (2002). On the simple and multiple relationship of creativity, achievement motivation, and self-esteem with entrepreneurship among Shahid Chamran University students. Journal of Education and Psychology, 3(3,4), 1-24.

Siriwongs, P. H. (2015). Developing Students' Learning Ability by Dint of Self-Directed Learning. Procedia Social and Behavioral Sciences, 197, 2074 - 2079.

Steinmayr, R., \& Spinath, B. (2009). The Importance of Motivation as a Predictor of School Achievement. Learning and Individual Differences, 19, 80-90.

Steinmayr, R., Meibner, A., Weidinger, A. F., \& Wirthwein, L. (2015). Academic Achievement. OXFORD BIBLIOGRAPHIES.

Stipek, D. (2002). Motivation to Learn (from Theory to Practice), translated by Hassanzadeh, R. and Ammoyi, N. (2001), Mashhad, World of Research.

Teo, T., Tan, S. C., Lee, C. B., Chai, C. S., Koh, J. H. L., Chen, W. L., et al. (2010). The self-directed learning with technology scale (SDLTS) for young students: An initial development and validation. Computers and Education, 55, 1764-1771.

Tondeur, J. (2007). Curricula and the use of ICT in education, two worlds apart. British Journal of Educational Technology, 39(7).

Torabi, F. (2012). On the Comparison of the effects of different types of motivational intervention on acquisition, retention, and transfer of free throw shooting in basketball. Motor Behavioral Journal, 11, 163-176.

Tuckman, B. W. (2014). Group versus Goal-Setting Effects on the Self-Regulated Performance of Students 
Differing in Self-Efficacy. The Journal of Experimental Education, 58(4), 291-298.

Watts, M., \& Lloyd, C. (2004). The use of innovative ICT in the active pursuit of literacy. UK: University of Surrey Roe Hampton.

Weinberg, R. (2010). Making Goals Effective: A Primer for Coaches. Journal of Sport Psychology in Action, $1(2), 57-65$.

Yuan, H. B., Williams, B. A., \& Fang, J. B. (2011). Chinese Baccalaureate Nursing Students' Readiness for Self-Directed Learning. Nurse Education Today, 8(2), 61-70.

Yuchiung, H., \& Ya-ming, S. (2005). The Effect of Self-Directed Learning Readiness on Achievement Comparing Face-to-Face and Two Way Distance Learning Instruction. International Journal of Instructional Media, 32(2), 143-155.

Zamini, S., Hosseininasab, D., \& Hashemi, T. (2007). On the effectiveness of planned nervous-verbal strategies in achievement on students' motivation and academic achievement. Journal of Qualitative Research in Health Sciences, 1(3).

Zika, S., \& Chamberlain, K. (1992). On the relation between meaning in life and psychological well-being. British Journal of Psychology, 133- 145.

\section{Copyrights}

Copyright for this article is retained by the author(s), with first publication rights granted to the journal.

This is an open-access article distributed under the terms and conditions of the Creative Commons Attribution license (http://creativecommons.org/licenses/by/4.0/). 